\title{
Amend Pandemic Preparedness Legislation to Prioritize Diagnostic Test Development and Deployment
}

\section{Grace Chesmore ${ }^{1^{*}}$, Kelsey Diffley ${ }^{2}$, Lirong Shi ${ }^{*}$}

1 University of Michigan, Department of Physics, Ann Arbor, MI

2University of Michigan, Department of Chemistry, Ann Arbor, MI

*All authors contributed equally http://doi.org/10.38126/ISPG170204

Corresponding author: lirongs@umich.edu

Keywords: pandemic; preparedness; diagnostic testing; PAHPAI; medical countermeasures

Executive Summary: As the world becomes increasingly globalized, the propensity of pandemics, such as COVID-19, increases. The United States Pandemic and All-Hazards Preparedness and Advancing Innovation Act of 2019 (PAHPAI) details the federal response to a health crisis including pandemics. The PAHPAI has hindered the nation's response to COVID19 due to its lack of emphasis on diagnostic testing (Burr 2019). Rapid testing is critical to slowing the spread of this disease. Ample testing will identify infected populations and will allow communities to take necessary precautions such as staying home and avoiding contact with others. Widespread shelter in place would not be necessary to control the spread of the virus, therefore reducing the economic impact of the pandemic. We propose Congress amends the PAHPAI to institute an improved testing response for future pandemics.

\section{A pandemic's impact on public health and} economic stability

The COVID-19 pandemic is an immense public health crisis. In the United States, there have been over 2 million cases and 110,000 deaths with no end in sight (Johns Hopkins University May 2020). The social and economic impact of this virus is also severe, which mainly resulted from the shelter-at-home lockdown practices. Such practices were deemed necessary to limit infection rates but have caused other issues. For example, police reports in Brookhaven, GA have shown a $16 \%$ increase in domestic violence and $800 \%$ increase in suicide related incidents as compared to the same period in 2018 (Reporter Newspapers 2020). By the end of March, the U.S. saw its highest level of seasonally adjusted unemployment claims since 1982 (Department of Labor 2020), with the unemployment rate increasing to $14.7 \%$ and the number of unemployed persons rising to 23.1 million in April (U.S. Bureau of Labor Statistics 2020). These issues are all due to sluggish diagnostic testing implementation.
In contrast, other hard hit countries, such as South Korea (Normile 2020) and Iceland (Kolbert 2020), have now mitigated active cases of COVID-19 or eliminated this disease within their border through universal test deployment and subsequent fast contact tracing (Figure 1). By May, Iceland had tested nearly $15 \%$ of its population and in June saw one of the lowest COVID death rates in the world: $0.56 \%$ (Kolbert 2020). The extensive testing, disclosure, and

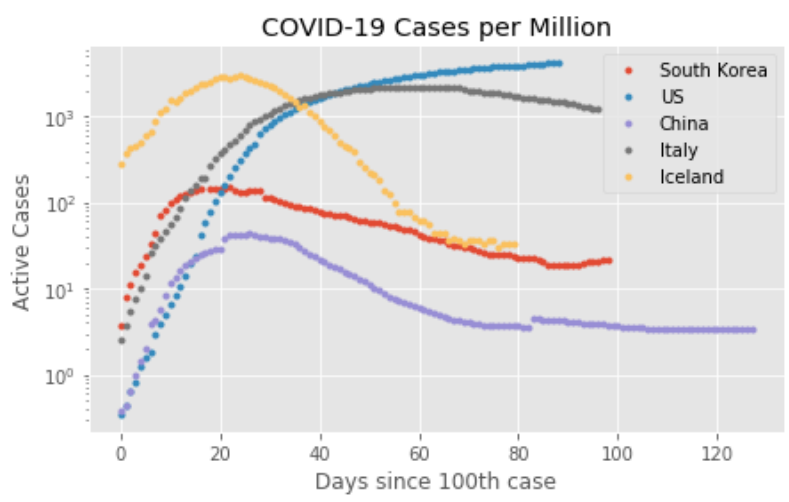

Figure 1: Active cases after the 100th reported case (CSSE at Johns Hopkins University 2020). 
contact tracing implemented in South Korea is predicted to result in 50\% lower economic losses than the full lockdown model implemented in the United States (Argente 2020).

\section{Limited testing interest in pandemic preparedness legislation}

The focus of current legislation for pandemic preparedness overlooks preventative measures, such as fast, widely available viral testing, that would eliminate the need for a response leading to negative social and economic impacts. Instead, it focuses on a threat-based approach, prioritizing preparation for bioterrorism and development for medical countermeasures such as treatments and vaccines (42 U.S.C. 300 hh-10 n.d). The Nation Health Security Strategy (NHSS), created by the legislation, acknowledges the risk of a global pandemic, stating "early detection and response fundamental to saving lives and reducing medical costs and economic impact" (Department of Health and Human Services 2019). However, neither the NHSS nor the PAHPAI specifies a plan for early detection by nationwide deployment of testing. Fast test deployment is critical to combating a pandemic as observed in the 2009 H1N1 epidemic (see Appendix). However, this positive response was not seen during COVID-19. The variation of response indicates a need for a plan for nationwide testing that would alleviate the social and economic impacts from shelter in place orders.

\section{Policy options} i. Option 1: Amend the PAHPAI for fast-track test
deployment

Amending PAHPAI to exempt diagnostic tests from Section 564 of the Federal Food, Drug, and Cosmetic act will allow for expedited test deployment by allowing for test development by private companies and test approval by state and local government during a declared pandemic. Rather than the FDA approving all tests, the FDA would set requirements for state officials to follow. The successful response seen in the $2009 \mathrm{H} 1 \mathrm{~N} 1$ pandemic was due to fast and efficient, nationwide test deployment. This option seeks to replicate that response in allowing test development and deployment to occur at the state level.

\section{Advantages}

- The standards for the FDA to approve a sample do not have to be relaxed, i.e. the integrity of medical countermeasures (MCMs) is not compromised.

- The amendment is intended to free up the FDA for focusing on further MCMs, such as vaccinations research.

- The amendment will hasten the response time for deploying tests to more states and provide more time for the FDA to produce a vaccine.

\section{Disadvantages}

- A de-localized system of diagnostic testing presents the risk of inconsistent research and safety procedures.

- There may be less accountability for scientists from local and state organizations to follow FDA procedures, as these will be scientists who do not work full time for the FDA but are being hired during a national emergency.

- Test approval at the local level could lead to an uneven distribution of tests across the nation. Individual companies seeking the approval state by state would further exacerbate this uneven distribution of testing.

ii. Option 2: Amend the PAHPAI to focus available funding on diagnostic testing

Amending 42 U.S.C. 300hh-10(b)(4)(F), Coordination of Grants and Agreements, under the PAHPAI (42 U.S.C. $300 \mathrm{hh}-10$ n.d) would create a stipulation in the Epidemiology and Laboratory Capacity for Prevention and Control of Emerging Infectious Disease (ELC) Program where a portion of funds would be dedicated to research and development of diagnostic tests. The goal would be for each state to receive the typical funding from the ELC Program, but with a portion of that funding dedicated to developing and distributing tests. This option seeks to establish a system for test development even when not in a current pandemic. As with Policy Option 1, such a system seeks to replicate the H1N1 pandemic response of fast, widely-available viral testing.

\section{Advantages}

- The amendment would strengthen testing ability by creating an incentive for research to be done specifically on testing rather than the apparent focus of MCMs. 
- This amendment would also strengthen a state-level response, providing states with an infrastructure to test quickly and effectively in response to a pandemic.

\section{Disadvantages}

- Emphasizing a state-level response will further differentiate states' capacities for disease response. Certain states already receive more funding than others, and thus could be better prepared than others.

- The amendment would remove control from the experts at the Centers for Disease Control (CDC), who would do better in ensuring response equality nationwide.

- Funding the research to develop a test would inevitably remove funding for other medical countermeasures such as vaccines.

\section{iii. Option 3: Inaction}

The PAHPAI outlines the U.S.'s response to a pandemic, detailing that the FDA will have complete jurisdiction over both a virus' vaccination and test research, resulting in equal development of vaccines and testing for a pandemic. Without a statutory change, pandemic response will continue as described by the PAHPAI, as illustrated during the 2009 H1N1 outbreak.

\section{Advantages}

- To control the spread of a pandemic in the US, a unified national response is required. As COVID-19 spreads disproportionately across the nation, having a state level response would be highly varied and ineffective at controlling the spread and saving lives.

\section{Disadvantages}

- Inaction will prohibit rapid testing needed to track how a pandemic is spreading in the US. As seen in the H1N1 outbreak, rapid testing procedures can alter the course of the viral impact on a community.

- In comparison to other nations during the COVID-19 outbreak, our preventative measures were not sufficient to weaken the spread as efficiently as some other countries.

- Maintaining complete authority at the federal level to develop and distribute tests may hinder the rapid response needed during a pandemic.

\section{Policy recommendation: Amend the PAHPAI for make fast-track test deployment}

We recommend that Congress approve Option 1. This statutory change has the advantage of maintaining the FDA's standards for approving tests as well as allowing the FDA to focus more on preventative MCMs such as vaccines. Though a delocalized system of diagnostic testing runs the risk of inhomogeneous practices, the pertinent need for testing overrides this risk when coupled to established FDA and CDC guidelines. Regional testing by government scientists will create a faster turnaround for private testing approval, and therefore will increase the number of tests, which is vital to dampening the spread of a pandemic as seen in the ongoing COVID-19 outbreak. While this state-level system could cause inconsistencies across the nation, in an event the national response is ineffective at containing a pandemic this option will be vital to preventing social and economic destruction.

\section{Appendix: Comparison of COVID-19 to H1N1}

The 2009 H1N1 response is a stark contrast to the COVID-19 pandemic as testing was available and deployed rapidly. The real-time PCR test developed by the CDC was cleared for use by diagnostic laboratories at the FDA under an Emergency Use Authorization on April 28, 2009, less than two weeks after the identification of the virus (Centers for Disease Control 2010). Compared with the spread of H1N1, delayed reaction from the CDC and flaws in preliminary test kits postponed the US response to the current pandemic. The lack of initial testing allowed the coronavirus to spread unimpeded through the US population. COVID-19 has a higher fatality rate and is much more contagious than H1N1 (Ries 2020), the need for fast and effective testing has to be emphasized. Members of Congress must evaluate how to make diagnostic testing a priority during a pandemic as seen in the $2009 \mathrm{H} 1 \mathrm{~N} 1$ response. The options include amending the PAHPAI to include FDA exemption or dedication of funding. 


\section{References}

Argente, David, Chang-Tai Hsieh, and Munseob Lee. "The Cost of Privacy: Welfare Effect of the Disclosure of COVID-19 Cases." The National Bureau of Economic Research, May 2020. https://doi.org/10.3386/w27220

"Brookhaven police see uptick in suicide, domestic violence incidents during pandemic; encounter spitting suspects." Reporter Newspapers, Apr 15, 2020.

https://www.reporternewspapers.net/2020/04/ 15/brookhaven-police-see-uptick-in-suicidedomestic-violence-incidents-during-pandemicencounter-spitting-suspects/

Bump, Philip. 2020. "Analysis | Why the United States Is Emerging as the Epicenter of the Coronavirus Pandemic." The Washington Post. WP Company. March 25, 2020. https://www.washingtonpost.com/politics/2020 103/25/why-united-states-is-emergingepicenter-coronavirus-pandemic/

Burr, Richard. 2019. "Text - S.1379 - 116th Congress (2019-2020): Pandemic and All-Hazards Preparedness and Advancing Innovation Act of 2019." Congress.gov. June 24. https://www.congress.gov/bill/116thcongress/senate-bill/1379/text

"CDC - ELC Cooperative Agreement - DPEI - NCEZID." 2020. Centers for Disease Control and Prevention. Centers for Disease Control and Prevention. April 3. https://www.cdc.gov/ncezid/dpei/epidemiology -laboratory-capacity.html

"C.D.C. Gives New Guidelines, New York to Close Restaurants and Schools and Italian Deaths Rise." 2020. The New York Times. The New York Times. March https://www.nytimes.com/2020/03/15/world/ coronavirus-live.html

The Center for Systems Science and Engineering (CSSE) at Johns Hopkins University https://coronavirus.jhu.edu/map.html

Department of Health and Human Services. "National Health Security Strategy 2019-2022". Accessed March 27, 2020.

https://www.phe.gov/Preparedness/planning/a uthority/nhss/Documents/NHSS-Strategy508.pdf

Gao, George F, Chen Wang, and Peter W Horby. 2020. "A Novel Coronavirus Outbreak of Global Health Concern." The Lanclet 395 (January). https://doi.org/10.1016/S0140-6736(20)30185$\underline{9}$
Giovanetti, Marta, Domenico Benvenuto, Silvia Angeletti, and Massimo Ciccozzi. 2020. "The First Two Cases of 2019-NCoV in Italy: Where They Come from?" Journal of Medical Virology 92 (5): 518-21. https://doi.org/10.1002/jmv.25699

Kapner, Suzanne. 2020. "Coronavirus Has Shut Stores, and Retailers Are Running Out of Time." The Wall Street Journal. Dow Jones \& Company. April 8. https://www.wsj.com/articles/coronavirus-hasshut-stores-and-retailers-are-running-out-oftime- 11586338200

Kolbert, Elizabeth. "How Iceland Beat the Coronavirus." The New Yorker. June 1, 2020. https://www.newyorker.com/magazine/2020/0 6/08/how-iceland-beat-thecoronavirus?utm_source $=$ nl\&utm brand=tny\&ut m mailing=TNY Magazine 060820\&utm_campai gn=aud-

dev\&utm medium $=$ email\&bxid=5bea0aa73f92a 4 $04694 \mathrm{~d} 6443 \& \mathrm{cndid}=54809805 \&$ hasha $=32112 \mathrm{df}$ 2482f0ce4ea7086da1752c09f\&hashb $=532 \mathrm{~d} 3846$ 87409b440f350f305be30affd3660090\&hashc $=$ af 19d49bd1666d1f732b0e5132519d2155c92a8c8 Ofe42820d708c1c9c320519\&esrc=newslettersform-sig\&utm term=TNY Magazine

Li, Ruiyun, Sen Pei, Bin Chen, Yimeng Song, Tao Zhang, Wan Yang, and Jeffrey Shaman. 2020. "Substantial Undocumented Infection Facilitates the Rapid Dissemination of Novel Coronavirus (SARS-CoV2)." Science 368 (6490): 489-93. https://doi.org/10.1126/science.abb3221

“Mapping COVID-19." 2020. CSSE. Accessed May 27, 2020. https://systems.jhu.edu/research/publichealth/ncov/

Normile, Dennis. "Coronavirus Cases Have Dropped Sharply in South Korea. What's the Secret to Its Success?" Science. March 18, 2020. https://www.sciencemag.org/news/2020/03/co ronavirus-cases-have-dropped-sharply-southkorea-whats-secret-its-success

Oh, Sunny. 2020. "Stocks Record Worst Week Since Financial Crisis as Coronavirus Concerns Heat Up." MarketWatch. MarketWatch. February 28. https://www.marketwatch.com/story/stocksrecord-worst-week-since-financial-crisis-ascoronavirus-concerns-heat-up-2020-02-28

Ries, Julia. 2020. "Here's How COVID-19 Compares to Past Outbreaks." Healthline. March 12, 2020. https://www.healthline.com/health-news/howdeadly-is-the-coronavirus-compared-to-pastoutbreaks\#2009-(H1N1)-flu-pandemic 
Timberg, Craig and Drew Harwell. 2020. "The New Coronavirus Economy: A Gigantic Experiment Reshaping How We Work and Live." The Washington Post. WP Company. March 21, 2020. https://www.washingtonpost.com/business/202 0/03/21/economy-change-lifestyle-coronavirus/

"Unemployment Insurance Weekly Claims." 2020, March. https://www.dol.gov/sites/dolgov/files/OPA/ne wsreleases/ui-claims/20200510.pdf

"Unemployment rate rises to record high 14.7 percent in April 2020." U.S. Bureau of Labor Statistics. May 13, 2020.

https://www.bls.gov/opub/ted/2020/mobile/u nemployment-rate-rises-to-record-high-14point-7-percent-in-april-2020.htm

Whalen, Jeanne and Bhattarai, Abha. 2020. "U.S, Companies Face Crucial Test Over China's Factory Shutdown." The Washington Post. February 25, 2020. https://www.washingtonpost.com/business/202 0/02/25/us-companies-so-far-are-survivingchinas-factory-shutdown-next-few-weeks-arecrucial/
"The 2009 H1N1 Pandemic: Summary Highlights, April 2009-April 2010." 2020. Centers for Disease Control and Prevention. Centers for Disease Control and Prevention. Accessed May 27. https://www.cdc.gov/h1n1flu/cdcresponse.htm

"42 U.S. Code $\S 300 \mathrm{hh}-10$ - Coordination of Preparedness for and Response to All-Hazards Public Health Emergencies." 2020. Legal Information Institute. Legal Information Institute. Accessed May 27. https://www.law.cornell.edu/uscode/text/42/3 $\underline{00 \mathrm{hh}-10}$

Grace Chesmore is a PhD candidate in Physics at the University of Chicago studying cosmology, focusing on optical systematics and design for the Simons Observatory. She holds an M.S. in Physics from the University of Michigan and a B.A. in Physics from Santa Clara University.

Lirong Shi is a PhD candidate in Chemistry at the University of Michigan doing spectroscopic study about surface chemistry. She is also pursuing a Science, Technology and Public Policy graduate certificate and interested in all kinds of policy-making. She holds a B.S. in Chemistry from Nanjing University.

Kelsey Diffley is a Ph.D. candidate in Chemistry at the University of Michigan studying the selectivity and regulation of histone deacetylases. She has additionally completed a graduate certificate in Science, Technology, and Public Policy at the University of Michigan and holds a B.S. in Chemistry from Carnegie Mellon University.

\section{Acknowledgements}

The authors would like to acknowledge Molly Spencer at the Gerald R. Ford School of Public Policy Writing Center at the University of Michigan for her helpful writing and editing feedback. The authors would also like to acknowledge the National Science Policy Network for the organization of the international policy memo writing competition and to the Science, Technology, and Public Policy Program/InSPIRE at the University of Michigan for introducing us as a team. Lastly, the authors would like to acknowledge JSPG editor Grant S. Hisao for his feedback during the revision. 